\title{
SUB-MASSIVE PULMONARY THROMBOEMBOLISM WITH OUT DEEP VEIN THROMBOSIS
}

\author{
Seetharam Vankudoth, Madhurima banoth
}

\begin{abstract}
:
Venous thromboembolism, causing Pulmonary Embolism (PE), is one of the major cardiovascular causes of death. We are reporting three cases of pulmonary thromboembolism without deep vein thrombosis and with normal levels of homocysteine, protein $C$ and $S$, anti-thrombin III levels. All three cases managed with thrombolysis with streptokinase, out of three cases two cases systemic thrombolysis given and one case catheter guided thrombolysis given and discharged on oral anti-coagulant with target range of PT with INR 2-3.on subsequent follow-up one case was diagnosed lymphoma and he was treated successfully in our institution.

Keywords: Pulmonary Embolism, Venous thromboembolism, INR.
\end{abstract}

\section{INTRODUCTION}

Pulmonary embolism (PE) is the most severe complication of deep venous thrombosis (DVT). Because both conditions require anticoagulant treatment and clinical signs and symptoms are unreliable for diagnosing either DVT or PE [1] , About $50 \%$ of patients with proven proximal DVT have an associated PE, which is asymptomatic in $50 \%$ of cases [2,3]. On the other hand, in patients with proven acute PE, the prevalence of detectable "residual" DVT is largely unknown because no specific studies are available, and the very few studies in which such data can be found provide discrepant results, with the prevalence of DVT ranging from 13 to $93 \%[4,5]$. These discrepancies may be explained at least in part by the heterogeneity of the diagnostic criteria for PE and DVT both between and within these studies.

Article received on 03 OCT 2016, published on 31 OCT 2016.

Seetharam Vankudoth ${ }^{1}$, Madhurima banoth. ${ }^{2}$

1 Senior Resident, Department of Cardiology, NIMS, India

2 Junior Resident, Department of Radiology, Osmania, India

Corresponding author: Seetharam Vankudoth,

Email: $\underline{\text { sitaramdm14@gmail.com }}$

\section{CASE REPORT}

A 83 year sedentary male presented with acute onset shortness of breath since one week with chest discomfort. he was a never smoker without a personal or family history of any clotting disorder.no history of diabetes mellitus, hypertension and coronary heart disease in past and there was no history of deep vein thrombosis.

On examination patient was tachypneic, tachycardia, BP was $100 / 60 \mathrm{~mm} \mathrm{Hg}$, Saturation was $81 \%$ on room air. All his peripheral pulses were well-felt. Patient's chest examination revealed bilaterally equal breath sounds with no adventitious sounds. Differential diagnosis of PTE was ruled out by appropriate investigations.

Investigations: $\mathrm{Hb}$ normal with mild leucocytosis, normal prothrombin time and activated prothrombin time, normal renal and liver function test. D-Dimer: positive was reported. His coagulation profile showed, protein-C and Protein-S, lipoprotein-A normal, serum homocysteine was normal, CRP $9.8 \mathrm{mg} \%$ [normal value: 0-5].Chest radiograph shows right lower zone, haziness with Hamptons hump (peripheral wedged-shaped density above the diaphragm), favouring the diagnosis of acute pulmonary embolism. Electrocardiogram (Figure 1) showed rest shows tachycardia, heart rate of 120/min with ' $\mathrm{P}$ ' pulmonale RV strain (' $\mathrm{T}$ ' wave inversion in V2-V3 most common abnormality), right bundle branch block, S1Q3T3, suggestive of acute pulmonary embolism. Echocardiography RV dysfunction with RV apical sparing (positive MaCconnell's sign) moderate tricuspid incompetence with mild pulmonary artery hypertension (PAP: 45 $\mathrm{mmHg}$ ) with IVS flattening with dilated RA/RV with good LV function. Venous Doppler study: Venous flow dynamics examined with Doppler imaging which is normal. Diagnosis was confirmed by CT pulmonary angiography which is suggesting of partial filling defect 
in main pulmonary artery and near total occlusion of right main pulmonary artery.

Patient was treated with fibrinolytic agent (streptokinase) in the dose of 1.5 lakh bolus followed by one lakh per hour for 24 hours along with oxygen supplementation, patient had drastic relief in his breathlessness and chest discomfort. Then he was started with enoxaparin (LMWH) $60 \mathrm{mg} 12$ hourly for 5 days and overlap with warfarin (oral anticoagulant) $5 \mathrm{mg}$ daily. Patient was discharged on 10th day on oral anticoagulants. He is doing well with regular follow-up for last 6 months with PT-INR around 2.

Figure 1: ECG- sinus tachycardia, right bundle branch block,S1Q3T3.

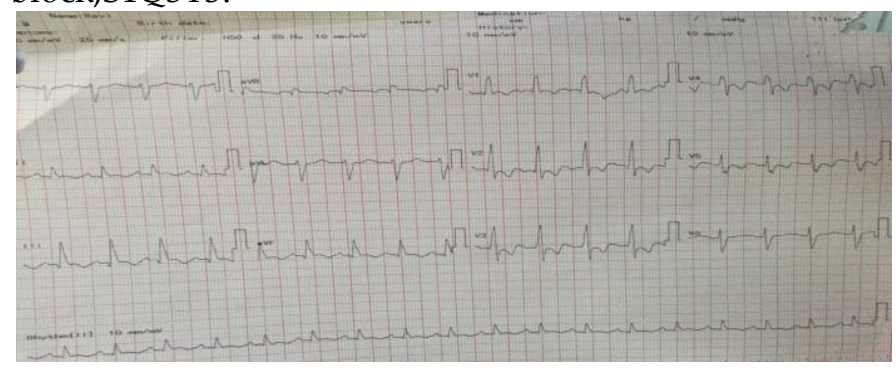

Figure 2: Right lower zone pulmonary infarct (wedge shape).

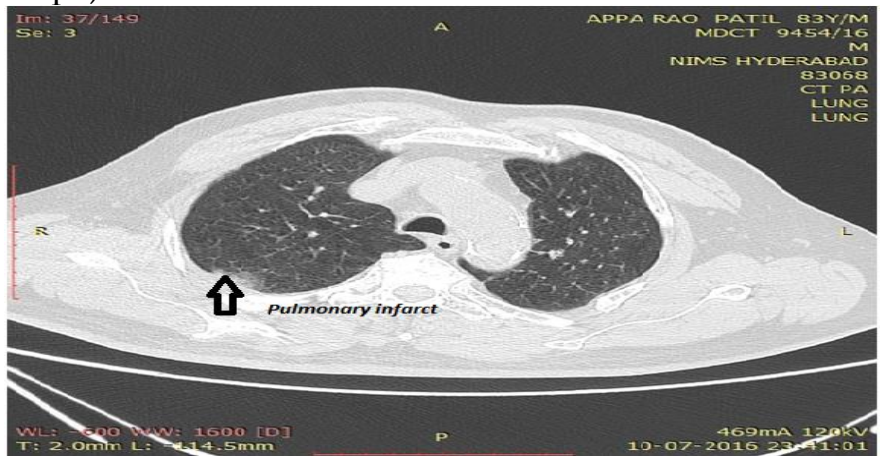

Figure 3:Partial filling defects in main pulmonary artery.

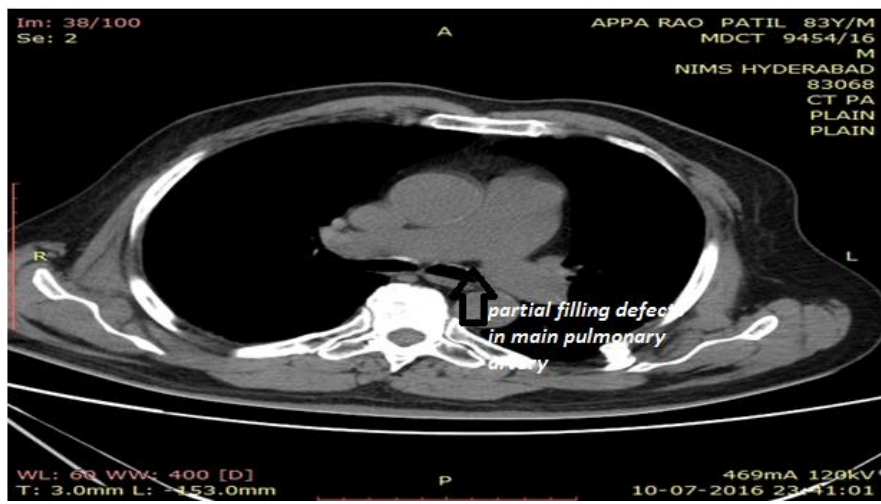

Figure 4: Near total occlusion of right descending pulmonary.

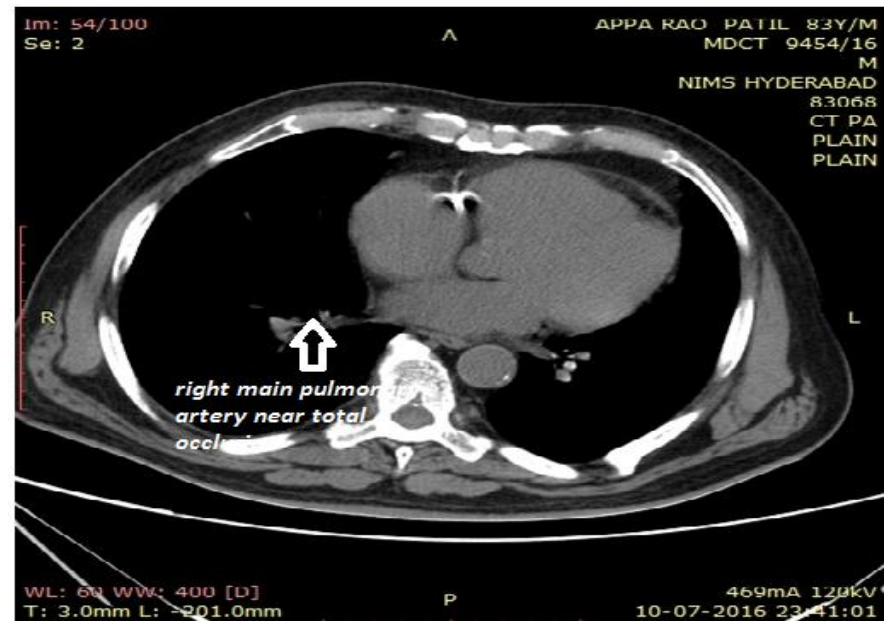

CASE REPORT 2 :

57 years old male patient not a diabetic, not a hypertensive not a smoker and alcoholic presented with history of sudden onset shortness of breath since 5 days which is class II, history of atypical chest pain since 3 days not associated with any radiating and not associated with sweating.

On examination patient was tachypnea, tachycardia with shock blood pressure of $80 / 50 \mathrm{~mm} / \mathrm{hg}$, on room air oxygen saturation was $80 \%$,patient was afebrile bilateral basal crepts were present Electro cardiogram suggesting resting tachycardia, right bundle branch block and $\mathrm{P}$ pulmonale, arterial blood gas suggestive of hypoxia with respiratory alkalosis, X-RAY suggestive of left mid and lower zone wedge shaped pulmonary infarcts present, 2D-echocardiography showing grossly dilated right atrium and ventricle with right ventricular dysfunction without pulmonary arterial hypertension, CTpulmonary angiography showing saddle thrombus present in main pulmonary artery bifurcation.

Other investigations normal haemoglobin with mild leucocytosis, renal and liver tests were normal, protein C and Protein $\mathrm{S}$ were normal, homocysteine and antithrombin III, ultrasound abdomen normal bilateral lower limb venous doppler normal.

Patient was treated with catheter guided thrombolysis with urokinase at the rate of 2.5 lakhs per hour for 24 hours given along with oxygen at the rate of $2 \mathrm{lit} / \mathrm{hr}$ and intra venous fluids given $50 \mathrm{ml} / \mathrm{hr}$. Patient was improved symptomatically and haemodynamically after 8 hours of thrombolysis. 
On subsequent follow-up he was diagnosed nonhodgkins lymphoma and he was treated successfully by chemotherapy and radiotherapy. Patient is on oral anticoagulant with target PT with INR of 2-3.

\section{CASE REPORT 3}

35 years old female patient presented with history of shortness of breath which is grade II since one week, which is more on exertion and not associated with paroxysmal nocturnal dyspnoea and orthopnoea. No history of chest pain palpitation, no history of diabetes mellitus and hypertension. History of using oral contraceptive pills since 6 months.

On examination patient was dyspnoeic with stable hemodynamics, on room air oxygen saturation was $85 \%$, electrocardiography showing sinus tachycardia, echocardiography showing dilated right atrium and right ventricle with good bi-ventricular function. Lower limb venous doppler was negative for thrombosis. We have confirmed diagnosis with help of CT-pulmonary angiography showing large thrombus obstructing left pulmonary artery.

After confirmation of diagnosis we have started intra venous thrombolysis with streptokinase for 24 hours subsequently kept her on oral anticoagulant. Patient was recovered completely and she is on our regular followup.

\section{DISCUSSION :}

Using the two gold standard diagnostic tests for pulmonary embolism and deep vein thrombosis we are reporting a case series of pulmonary thromboembolism without deep vein thrombosis. Very few published series allow the estimation of the prevalence of detectable DVT in patients with proven PE, and report a wide range of results (ranging from 13 to 93\%); The study by Kruit et al[6] provided slightly more detailed data: 38 of 41 patients (93\%) with high-probability lung scans had abnormal venogram, 33\% of DVTs were limited to the calf, and only $28 \%$ of patients with DVT showed signs or symptoms of thrombosis. Finally, in the THÉSÉE study [7], among 612 patients with acute symptomatic PE, 255 patients (42\%) had symptoms of DVT and 421 (72\%) had DVT diagnosed by venous US or venography. Exact proportions of patients with and without symptoms who actually had DVT were not reported.
In our case series one female patient had sub-massive pulmonary thromboembolism with history of use of oral contraceptive pills, other two cases are male patients with normal coagulation profile, on follow-up for 8 months one patient was diagnosed non Hodgkin lymphoma and he was treated with both chemo and radiotherapy, but all three cases venous Doppler was negative for thrombus with massive pulmonary thrombus on CT pulmonary angiography $[8,9]$.

However, whether the presence of detectable DVT in patients with acute PE is associated with a higher risk of recurrent $\mathrm{PE}$, leading one to consider IVC interruption, might remain a matter of debate. To the best of our knowledge, this risk has been assessed in only one prospective observational study [10] in which the overall 15-day risk of recurrent PE in 50 patients with both angiography-proven $\mathrm{PE}$ and venography-proven proximal DVT was found to be only $4 \%$, i.e. very close to the risk of PE in the overall population of patients with proximal DVT with or without associated PE[11,12].It seems likely, however, that the "very high-risk" patients who will develop a new (and potentially fatal) PE despite anticoagulant treatment belong to this subgroup $[11,13]$.

\section{CONCLUSION :}

In India, VTE is a common cause of mortality and morbidity in patients hospitalized for surgical or medical illnesses. It is often misdiagnosed and not treated in time. Signs and symptoms are nonspecific and high degree of clinical suspicion with right application of diagnostic tools both imaging and non-imaging are vital for definitive diagnosis. Chest CT has virtually replaced pulmonary angiography once considered gold standard for confirming diagnosis.

We are presenting 3 cases of pulmonary thromboembolism without deep vein thrombosis, all cases of pulmonary thromboembolism need not to be having deep vein thrombosis because of embolization from the site of thrombus.to knowing cause of thrombus is essential for anticoagulant duration of therapy.

\section{REFERENCES :}

1 Hirsh J, Hoak J. Management of deep vein thrombosis and pulmonary embolism: a statement for healthcare professionals. Circulation 1996; 93:2212-2245 
2 Monreal M, Rey-Joly Barroso C, Ruiz Manzano J, et al. Asymptomatic pulmonary embolism in patients with deep vein thrombosis: Is it useful to take a lung scan to rule out this condition? J Cardiovasc Surg (Torino) 1989; 30:104-107

3 Moser KM, Le Moine JR. Is embolic risk conditioned by location of deep venous thrombosis? Ann Intern Med 1981; 94:439-444.

4 Hull RD, Hirsh J, Carter CJ, et al. Pulmonary angiography, ventilation lung scanning, and venography for clinically suspected pulmonary embolism with abnormal perfusion lung scan. Ann Intern Med 1983; 98:891-899

5 Turkstra F, Kuijer PM, van Beek EJ, et al. Diagnostic utility of ultra sonography of leg veins in patients suspected of having pulmonary embolism. Ann Intern Med 1997; 126:775-781.

6 Kruit WH, de Boer AC, Sing AK, et al. The significance of venography in the management of patients with clinically suspected pulmonary embolism. J Intern Med 1991; 230: 333-339.

7 Simonneau G, Sors H, Charbonnier B, et al. A comparison oflow-molecular-weight heparin with unfractionated heparin for acute pulmonary embolism. N Engl J Med 1997; 337:663-669.

8 Perrier A, Desmarais S, Miron MJ, et al. Non-invasive diagnosis of venous thromboembolism in outpatients. Lancet 1999; 353:190-195.

9 Hyers TM, Agnelli G, Hull RD, et al. Antithrombotic therapy for venous thromboembolic disease: fifth ACCP consensus conference on antithrombotic therapy. Chest 1998; 114:561S-578S

10 Girard P, Mathieu M, Simonneau G, et al. Recurrence of pulmonary embolism during anticoagulant treatment: a prospective study. Thorax 1987; 42:481-486.

11 Decousus H, Leizorovicz A, Parent F, et al. A clinical trial of vena caval filters in the prevention of pulmonary embolism in patients with proximal deep-vein thrombosis. Prevention du Risqued'EmboliePulmonaire par Interruption Cave Study Group. N Engl J Med 1998; 338:409-415.

12 Hyers TM, Agnelli G, Hull RD, et al. Antithrombotic therapy for venous thromboembolic disease: fifth ACCP consensus conference on antithrombotic therapy. Chest 1998; 114: 561S-578S

13 Douketis JD, Kearon C, Bates S, et al. Risk of fatal pulmonary embolism in patients with treated venous thromboembolism. JAMA 1998; 279:458-462 